\title{
Pregabalin for the Management of Cervicogenic Headache: A Double Blind Study
}

\author{
Guy P. Boudreau, Luc Marchand
}

\begin{abstract}
Objectives: The primary objective was to evaluate the effects of pregabalin relative to placebo in patients with chronic unilateral cervicogenic headache. Primary and secondary end points: To assess the change from baseline in the frequency of cervicogenic headache days per 28-day period between placebo and treatment group. To assess the change from baseline in the intensity of headache, and health outcome measures. Study design: This was a double-blind, randomized, placebo-controlled, parallel-group study, evaluating the efficacy and safety of pregabalin in patients with cervicogenic headache. Procedures: The study consisted of two phases. A baseline of -28 days and a double-blind placebo-controlled phase: with an escalation and maintenance phase, during which patients remained at their highest dose until the end of the study, at Day 86. Results: Forty one patients were randomized, predominantly females, with a mean age of 52 years old. At screening, both groups had, on average, 26 headache-days per month. By the final phase of the study, the number of headache days dropped to 16 per month for the pregabalin group while remaining stable for the placebo group ( $\mathrm{p}=0.037)$. No serious adverse events were reported during the study. Conclusion: In this study, primary objectives were achieved with a statistically significant change of ten days in frequency of headache days; with minor side effects that were well tolerated.
\end{abstract}

RÉSUMÉ: La prégabaline dans le traitement de la céphalée cervicogénique : une étude à double-insu. Objectifs: Le but principal de cette étude était d'évaluer les effets de la prégabaline par rapport au placebo chez des patients présentant une céphalée cervicogénique unilatérale chronique. Critères d'évaluation primaires et secondaires: évaluer le changement dans la fréquence des jours avec céphalée cervicogénique par période de 28 jours par rapport à la fréquence avant traitement, entre le groupe recevant le placebo et le groupe recevant la prégabaline. évaluer le changement de l'intensité de la céphalée et des indicateurs de santé. Devis d'étude: Il s'agit d'une étude à double-insu, randomisée, contrôlée par placebo, en groupes parallèles, pour évaluer l'efficacité et la sécurité de la prégabaline chez des patients atteints de céphalée cervicogénique. Modalités d'étude: L'étude comportait deux phases : une phase prétraitement de 28 jours et une phase à double-insu, contrôlée par placebo, avec augmentation puis maintien de la dose, pendant laquelle les patients ont reçu la plus forte dose du médicament jusqu'à la fin de l'étude, soit au jour 86. Résultats: Quarante et un patients, dont l'âge moyen était de 52 ans et la majorité étaient des femmes, ont été randomisés. Au moment de l'admission dans l'étude, les deux groupes présentaient de la céphalée en moyenne 26 jours par mois. Pendant la phase finale de l'étude, le nombre de jours avec céphalée a chuté à 16 par mois pour le groupe recevant de la prégabaline alors qu'il est demeuré inchangé pour le groupe recevant le placebo $(\mathrm{p}=0,037)$. Aucun événement indésirable sérieux n'a été rapporté pendant l'étude. Conclusion: Les objectifs principaux de l'étude ont été atteints comme en témoigne la diminution de la fréquence des jours où la céphalée était présente, soit 10 jours de moins, sous prégabaline. Les patients ont présenté des effets secondaires mineurs, par ailleurs bien tolérés.

Keywords: Cervicogenic headache, $\mathrm{C} 2$ neuropathy, pregabalin, prophylactic treatment

doi:10.1017/cjn.2014.2

Can J Neurol Sci. 2014; 41: 603-610

\section{INTRODUCTION}

There is a growing body of literature on cervicogenic headache and an increasing acceptance that headache can originate from the cervical spine. Diagnostic criteria have been established by a variety of expert groups ${ }^{1-7}$ all of which agree that these headaches originate in the neck or occipital region and implicate cervical paraspinal tissues. Prevalence estimates range from $0.4 \%$ to $2.5 \%$, in the general population, and up to $15 \%$ to $20 \%{ }^{4,9}$ of patients with chronic daily headache. Cervicogenic headache affects four females for one male and peaks at a mean age of 42 . Although its etiology remains a source of controversy, $4,6,10,11$ structures implicated in the genesis of cervicogenic headache have their sensory input at the level of $\mathrm{C} 1-\mathrm{C} 2-\mathrm{C} 3$, and converge within the spinal nucleus of the trigeminal nerve to form the trigeminal-cervical complex, which is a common final pathway for many types of headache. ${ }^{12-14}$

Despite the significant impact of chronic daily cervicogenic headache, a relative paucity of studies has been published examining the use of pharmacotherapy for its relief. In our clinical experience chronic cervicogenic headache seems unresponsive to common headache medication.

From the Centre de Neurologie Ambulatoire (GPB, LM), Hôpital Notre-Dame, Montréal, QC, Canada

Received January 21, 2013. Revised March 19, 2013.

Correspondence to: Guy P. Boudreau, Centre de Neurologie Ambulatoire, Hôpital Notre-Dame, 1560 rue Sherbrooke Est, Montréal, QC, Canada. Email: guypboudreau@gmail.com 
Peripheral nerve injury, as may be occurring in cervicogenic headache, can lead to persistent neuropathic pain in which allodynia, hyperalgesia, hyperesthesia, hypoesthesia or dysesthesi a may develop. Experiments have demonstrated a marked up regulation of the alpha-2-delta calcium channel subunit after peripheral nerve injury ${ }^{13,15-18}$ and an improvement of tactile allodynia secondary to neuropathic injury when these calcium channel subunits are targeted ${ }^{19,20}$ for treatment. Systematic and pragmatic reviews have lamented the poor quality of the literature and the fact that most treatments lack a compelling evidence base. ${ }^{21}$ Given that pregabalin, a potent ligand for the alpha-2-delta calcium channel subunit that exhibits analgesic properties, ${ }^{22}$ we posited that it could be effective in reducing the frequency of chronic daily unilateral cervicogenic headache, caused by a $\mathrm{C} 2$ radiculopathy.

\section{Methods}

\section{Study Design}

The overall study design was a single center, double -blind, randomized, placebo-controlled, parallel-group study. The criteria of the Cervicogenic Headache International Study Group (7) were employed to diagnose patients. Clinical signs of $\mathrm{C} 2$ radiculopathy on the painful side only were obligatory.

Patients were randomized to placebo or to a pregabalin regimen (1:1) consisting of a flexible schedule with escalation based on patient's individual response and tolerability (30 days). The full study duration was 16 weeks: 4 weeks for the baseline period and 12 weeks of active treatment.

The study was conducted in compliance with good clinical practice guidelines and in accordance with the regulations of the declaration of Helsinki and approved by an institutional review board. Study subjects provided informed consent prior to enrollment.

\section{Subjects}

Sixty subjects, 18-70 years of age, were screened with the objective of randomizing 40 patients suffering chronic unilateral cervicogenic headache, and willing to participate in a placebocontrolled study for approximately 12 weeks, using pregabalin as the active drug. Inclusion criteria stipulated that patients suffer headache for more than three months, 15 or more headache days per four week period, with each day consisting of four or more hours of continuous headache of moderate to severe intensity measured with a numerical rating scale (NRS) defined as moderate (4-7/10 on NRS) to severe (8-10/10 on NRS) in both groups at screening, refractory to standard treatment such as neuromodulators, muscle relaxants, tricyclics, non steroidal anti inflammatory drugs since onset, with fifteen or more neck pain days per four week period, with each day consisting of four or more hours of continuous neck pain. Patients were further required to have an abnormal neck examination with clinical signs of neuropathic involvement (i.e., hyperesthesia, hypoesthesia, dysesthesia, allodynia or hyperalgesia on the painful side of the head and/or neck, in the C2 and C3 territory). Patients were excluded if they presented bilateral headaches, migraine, cluster headaches, hemicrania continua, or chronic paroxysmal hemicranias. Patients with a secondary headache in relation to any intracranial pathology, patients with secondary cervical pain in relation to tumors, neoplasm or infection were also excluded.
Also excluded from the study were all patients scheduled for somatic nerve blocks during their participation in the trial and patients who had undergone C2-C3 rhyzotomy by thermocoagulation of the medial sensory root, or facet joint, in the past six months. Patients were also excluded if they had undergone somatic nerve blocs of the neck in the past four weeks with a local anesthetic, or in the past six months with a local anesthetic and cortisone. Patients with fibromyalgia or those who had abused illicit drugs or alcohol within the last year and patients on a continuous opiate regimen for chronic pain or using episodic rescue medication for more than 15 days/month were excluded. Other exclusion criteria were a serious psychiatric condition, females who were pregnant or nursing and patients not using reliable contraception.

\section{Treatment}

Study medications consisted of pregabalin $75 \mathrm{mg}$ and $150 \mathrm{mg}$, capsules and matching placebo capsules, all identical in appearance in order to preserve study blinding. After a -28 day baseline period, patients were randomly assigned to their treatment regimens (pregabalin/placebo in a 1:1 ratio), according to a computer-generated randomization list. Following randomization, an escalation phase consisted of three consecutive ten-day periods during which the dose was escalated. Dosage could be increased in four steps $(150 \mathrm{mg}, 225 \mathrm{mg}, 300 \mathrm{~g}, 450 \mathrm{mg}$ ) but only decreased once (by only one step) during the escalation phase.

During the first 30 days on study treatment (escalation phase), two phone contacts were made, producing the three ten-day treatment periods. During each telephone contact the patients were instructed to return to the clinic for dose adjustment depending on individual tolerability and efficacy on the study medication and/or study medication replacement. If the patient had difficulty tolerating the escalated dose (i.e., $225 \mathrm{mg} /$ day), then the patient could return to $150 \mathrm{mg} / \mathrm{day}$, or choose to remain at $225 \mathrm{mg} /$ day. Patients who elected to escalate their dose were instructed to take $300 \mathrm{mg} / \mathrm{day}$ for seven days, and then $450 \mathrm{mg} /$ day (one $150 \mathrm{mg}$ capsule in the morning and two at night) for the following three days. Patients were contacted by the research assistant by telephone and were given a final opportunity to adjust their dose. During the maintenance phase, doses were fixed at $150 \mathrm{mg} /$ day, $225 \mathrm{mg} /$ day, $300 \mathrm{mg} /$ day, or $450 \mathrm{mg} /$ day without possibility of dose adjustment.

Patients were not allowed to use preventive medication for their head and neck pain within the 28 days prior to randomization. Rescue medication such as non steroidal anti-inflammatory drugs or combination analgesics were not allowed more than 12 days per month. Non-headache medications had to be at a stable dose for at least one month prior and during the conduct of the trial.

\section{Outcome measures}

The primary efficacy variable was change from baseline in frequency of chronic cervicogenic headache per each 28-day period during the maintenance phase. Change from baseline in intensity of cervicogenic headache during the maintenance phase was included as a secondary efficacy variable.

Health outcome measures were: headache diaries for frequency and intensity (NRS 1-10/10) of cervicogenic headache, Headache Impact Test (HIT-6). At baseline a mean total HIT-6 score of more 
than 60 indicates severe headache impact Each HIT-6 question scored as never (6) rarely (8) sometimes (10) very often (11) or always (13) will add to a total score of $36-78 .^{23}$ The Hospital Anxiety and Depression scale (HAD) is a structured auto questionnaire of 14 items, designed to identify the presence of anxiety and/or depression. ${ }^{24}$ With a score of less than 7 there is absence of psychopathology With a score of more than 8 specificity and sensitivity is high, with a maximum possible score of 21 . The higher the score, the more severe the pathology. The EQ-5D Visual analogue scale, is a self classified health state profile measuring quality of health in \% ( $0 \%$ being the worst and $100 \%$ being the best health state profile).

\section{Tolerability and safety}

Tolerability and safety measures were recorded in the Case Report Form for adverse events or serious adverse events. Adverse events were collected for 30 days following the final study visit. Physical examination, urine pregnancy tests (for all females of childbearing potential) and vital signs were monitored throughout the study. All adverse events occurring during the study were classified on the basis of Medical Dictionary for Regulatory Activities (MedDRA) terminology.

\section{Statistics}

For the purpose of statistical analyses, subjects were classified into one of the following groups: the modified intent-to-treat (mITT) population, the completers population, and the safety population.

The modified intent-to-treat (mITT) population consisted of all patients who received at least one dose of pregabalin or placebo and had at least one efficacy evaluation following a minimum of 14 days (owing to natural variations in cervicogenic headache frequency from week to week) of study medication during the maintenance phase of the study. All efficacy analyses (primary and secondary) were based on this population. The patients were analyzed according to the randomization assignment (pregabalin or placebo), regardless of actual treatment received.

Completers were patients who took study drug consistent with all study procedures and who had taken the study medication for the full 12 weeks. Confirmatory efficacy analyses were performed on this population.

Safety analysis included all patients assigned a subject number and who received at least one dose of study medication. The patients were analyzed according to the randomization assignment (pregabalin or placebo) regardless of actual treatment and dosage received.

\section{Handling of Missing Data}

During the maintenance phase, patients had to have a minimum of 14 efficacy measurements (i.e., days) for each 28-day period for efficacy analysis. If data was unavailable from the final 28-day period, then data from the patient's final 28 days on protocol was used (assuming at least 14 days of data was available). Patients with no on-treatment data for a parameter were excluded from the analysis of that parameter.

\section{Primary Efficacy Analysis}

The primary efficacy endpoint was the change from baseline in number of cervicogenic headache days per each 28-day period. A headache day was defined as a day (00:00 to 23:59) with four or more continuous hours of headache per patient diary. Comparison between treatment groups was conducted using an analysis of covariance adjusting for the baseline frequency of headache. ${ }^{25-27}$

\section{Study Success Criteria for Efficacy}

A conclusion of superiority of pregabalin relative to placebo was reached if the group differences in (baseline adjusted) mean changes from baseline to each 28-day period in frequency of cervicogenic headache for pregabalin were found to be statistically significantly decreased when compared to placebo.

\section{Non Parametric Analysis}

Other supplemental non-parametric analysis was performed. Tests of normality for the primary endpoint were performed. Assessments included histograms and QQ-plots as well as test checks for normality with the Shapiro-Wilk test and the Kolmogorov-Smirnov test. If the normality assumptions were not tenable, corresponding non-parametric methods were implemented.

Table 1: Patient disposition

\begin{tabular}{|c|c|c|c|}
\hline & Placebo $N=21$ & Pregabalin $N=20$ & Combined $N=41$ \\
\hline Patients: randomized & $100 \%(21)$ & $100 \%(20)$ & $100 \%(41)$ \\
\hline Population: mITT & $76 \%(16)$ & $90 \%(18)$ & $83 \%(34)$ \\
\hline Patients: excluded from mITT & $24 \%(5)$ & $10 \%(2)$ & $17 \%(7)$ \\
\hline Reasons for exclusion: No follow-up observations & $24 \%(5)$ & $10 \%(2)$ & $17 \%(7)$ \\
\hline Population: Completers & $48 \%(10)$ & $90 \%(18)$ & $68 \%(28)$ \\
\hline Patients: Discontinued & $52 \%(11)$ & $10 \%(2)$ & $32 \%(13)$ \\
\hline Reasons for discontinuation: Lost to follow-up & $18 \%(2)$ & $10 \%(2)$ & $31 \%(4)$ \\
\hline Other & $36 \%(4)$ & $0 \%(0)$ & $31 \%(4)$ \\
\hline Pregnancy & $9 \%(1)$ & $0 \%(0)$ & $8 \%(1)$ \\
\hline Withdrew consent & $36 \%(4)$ & $0 \%(0)$ & $31 \%(4)$ \\
\hline
\end{tabular}

mITT $=$ modified intent-to-treat

$\mathrm{N}=$ the number of subjects analysed. 
Table 2: Patient Demographics and Baseline Characteristics - mITT Population

\begin{tabular}{|c|c|c|c|c|}
\hline & Number & $\begin{array}{l}\text { Placebo } \\
\mathrm{N}=16\end{array}$ & $\begin{array}{c}\text { Pregabalin } \\
\mathbf{N}=18\end{array}$ & Test statistic \\
\hline Age (years) & 34 & 36.145 .556 .7 & $49.4 \mathbf{5 8 . 3} 62.9$ & $\mathrm{P}=0.04^{1}$ \\
\hline Patient's Gender: & 34 & & & $\mathrm{P}=0.897^{2}$ \\
\hline Male & & $31 \%(5)$ & $33 \%(6)$ & \\
\hline Female & & $69 \%$ (11) & $67 \%$ (12) & \\
\hline Predominant Ethnicity: & 34 & & & $\mathrm{P}=0.932^{2}$ \\
\hline Caucasian & & $94 \%(15)$ & $94 \%$ (17) & \\
\hline Hispanic & & $6 \%(1)$ & $6 \%(1)$ & \\
\hline Height $(\mathrm{cm})$ & 31 & 160165177 & 153160170 & $\mathrm{P}=0.152^{1}$ \\
\hline Weight $(\mathrm{Kg})$ & 33 & 60.468 .277 .0 & 68.675 .578 .2 & $\mathrm{P}=0.319^{1}$ \\
\hline Triggering factor: & 34 & & & \\
\hline trauma & & $85 \%(14)$ & $85 \%(15)$ & \\
\hline Work related & & $15 \%(2)$ & $15 \%(3)$ & \\
\hline
\end{tabular}

\section{Secondary Efficacy Endpoint Analysis}

The secondary efficacy endpoints were the change from baseline in intensity of cervicogenic headache during the maintenance phase. The mean intensity for each period (screening, escalation, maintenance) was determined, using the numerical rating scale (NRS). Formal statistical testing was based on the results from a linear mixed model for repeated measures. This mixed model expressed the (mean) headache intensity as a linear function of treatment, time, treatment-by-time interaction, screening phase (baseline) headache intensity, and a random patient effect. The difference between treatment groups was expressed by the treatment-by-time interaction.

The frequency of headache was based on the results from a linear mixed model. The HIT-6 for the impact of headache on patients' lives was determined with a linear mixed model for repeated measures as above. The HAD scale for depression and anxiety, with an analysis of covariance adjusting for the baseline HAD score. The EQ-5D, was assessed with the health states converted into a weighted health state index by applying scores from the EQ-5D preference weights elicited from general United States population samples in order to give an EQ-5D index score to be analyzed with a t-test, as well as for the visual analog scale (VAS)-based health state score. The presence of over dispersion was checked and accounted for the patient's Global Impression of Change (PGIC), with treatment groups compared.

\section{RESULTS}

\section{Populations and demographics}

Pregabalin and placebo groups were similar. Forty one patients were randomized, 34 were part of the mITT population (18 pregabalin, 16 placebo), Table 1 . Sixty seven percent of patients were females and $33 \%$ were males. Ninety four percent of patients were Caucasian, and $6 \%$ were Hispanic. The mean age of patients in the placebo group was 45 years old and in the pregabalin group the subjects mean age was 58 years-of-age, Table 2. No patients suffered migraine but two patients had a family history of headache. More placebo patients than pregabalin patients discontinued the study for lack of efficacy. Neurologic and musculoskeletal abnormalities at baseline were not different between the two groups. The maximum dose of pregabalin for efficacy and tolerability was a $450 \mathrm{mg} /$ day regimen, Table 3.

\section{Primary efficacy endpoints}

Both groups had on average 26 headache-days per 28 day period at screening. This number dropped to 16 for the pregabalin group by the end of the study while remaining stable for the placebo group, Table 4. There was, however, no statistical difference between groups for the first 28 -day period $(\mathrm{p}=0.058)$, while the pregabalin group had significantly less headache-days during the second period $(\mathrm{p}=0.013))$, compared to the placebo group.

Table 3: Pregabalin doses achieved after escalation - m-ITT population

\begin{tabular}{|c|c|c|c|}
\hline & $\begin{array}{c}\text { Placebo } \\
N=16\end{array}$ & $\begin{array}{c}\text { Pregabalin } \\
\mathbf{N}=\mathbf{1 8}\end{array}$ & $\begin{array}{c}\text { Combined } \\
\mathrm{N}=34\end{array}$ \\
\hline \multicolumn{4}{|c|}{ Maximum Dose Achieved 34} \\
\hline $150 \mathrm{mg} / \mathrm{day}$ & $0 \%(0)$ & $17 \%(3)$ & $9 \%(3)$ \\
\hline $225 \mathrm{mg} /$ day & $0 \%(0)$ & $11 \%(2)$ & $6 \%(2)$ \\
\hline $300 \mathrm{mg} / \mathrm{day}$ & $6 \%$ & $22 \%(4)$ & $15 \%(5)$ \\
\hline $450 \mathrm{mg} /$ day & $75 \%(12)$ & $50 \%(9)$ & $62 \%(21)$ \\
\hline NA & $19 \%(3)$ & $0 \%(0)$ & $9 \%(3)$ \\
\hline
\end{tabular}

$\mathrm{N}=$ the number of subjects analysed. 
Table 4: Frequency of Headache-Days/month - mITT Population

\begin{tabular}{|c|c|c|c|c|}
\hline & Statistics & $\begin{array}{l}\text { Placebo } \\
(\mathrm{N}=16)\end{array}$ & $\begin{array}{c}\text { Prégabalin } \\
(\mathbf{N}=18)\end{array}$ & p-value \\
\hline \multirow[t]{3}{*}{ Screening } & $\mathrm{N}$ & 16 & 18 & 0.76 \\
\hline & Mean & 26.6 & 26.3 & \\
\hline & SD & 2.45 & 3.21 & \\
\hline \multirow[t]{3}{*}{ Escalation } & $\mathrm{N}$ & 16 & 18 & 0.051 \\
\hline & Mean & 26.7 & 23.3 & \\
\hline & SD & 2.88 & 6.21 & \\
\hline \multirow[t]{3}{*}{ Maintenance (first 28 days) } & $\mathrm{N}$ & 11 & 18 & 0.058 \\
\hline & Mean & 23.7 & 18.6 & \\
\hline & SD & 4.75 & 9.05 & \\
\hline \multirow[t]{3}{*}{ Maintenance (second 28 days) } & $\mathrm{N}$ & 11 & 17 & 0.013 \\
\hline & Mean & 24.1 & 16.3 & \\
\hline & SD & 5.60 & 9.86 & \\
\hline
\end{tabular}

$\mathrm{N}=$ the number of subjects analysed. Test used: t-test

\section{Secondary end points}

The treatment-by-time for the intensity of cervicogenic headache between the two groups showed a statistical difference, Table 5. During the baseline phase, the mean pain intensity was of moderate intensity (4-7/10 on the NRS). During the maintenance phase, for the pregabalin group, mean pain intensity changed from moderate pain to mild pain (1-3/10 on NRS) of short duration mostly upon awakening, compared to the placebo group that continued with a moderate intensity (4-7/10 on NRS) of pain throughout the day.

We assessed change from baseline in Headache-Related disability. The HAD scores and the HIT- 6 scores are seen in Table 6 and the EQ-5D VAS self-classified health state profiles are presented in Table 7.
For the global impression of change there was a significant difference between the two treatment groups $(p=0.015)$. Patients on pregabalin said they improved more ( $85 \%$ improved ) than the placebo group (23\% on placebo). Safety analysis included all patients assigned a subject number and who received at least one dose of study medication. There were no serious adverse events, $5 \%$ of patients on placebo and pregabalin had severe adverse events, $15 \%$ on placebo and $35 \%$ on pregabalin suffered moderate adverse events and $35 \%$ of patients on pregabalin had mild adverse events, Table 8 and 9 .

\section{Discussion}

Headaches, frequently occipital or hemicranial, may be associated with disorders of the cervical spine. ${ }^{28}$ The term cervico-

\section{Table 5: Intensity of headache - mITT Population}

\begin{tabular}{|c|c|c|c|c|}
\hline & Statistics & $\begin{array}{l}\text { Placebo } \\
(N=16)\end{array}$ & $\begin{array}{c}\text { Pregabalin } \\
(\mathbf{N}=18)\end{array}$ & p-value \\
\hline \multirow[t]{3}{*}{ Screening } & $\mathrm{N}$ & 16 & 18 & 0.572 \\
\hline & Mean & 5.7 & 5.5 & \\
\hline & $\mathrm{SD}$ & 1.52 & 1.26 & \\
\hline \multirow[t]{3}{*}{ Escalation } & $\mathrm{N}$ & 16 & 18 & 0.137 \\
\hline & Mean & 5.2 & 4.3 & \\
\hline & $\mathrm{SD}$ & 1.47 & 1.83 & \\
\hline \multirow[t]{3}{*}{ Maintenance (first 28 days) } & $\mathrm{N}$ & 11 & 18 & 0.387 \\
\hline & Mean & 4.5 & 2.9 & \\
\hline & $\mathrm{SD}$ & 1.62 & 1.83 & \\
\hline \multirow[t]{3}{*}{ Maintenance (second 28 days) } & $\mathrm{N}$ & 11 & 17 & 0.062 \\
\hline & Mean & 4.7 & 2.0 & \\
\hline & SD & 2.11 & 1.96 & \\
\hline
\end{tabular}

$\mathrm{N}=$ the number of subjects analysed. Test used: $\mathrm{t}$-test

NRS scale of 10 (1-3/10: mild) (4-7/10: moderate) (8-10/10: severe); $\mathrm{SD}=$ standard deviation 
Table 6: Change from baseline in headache-related disability: Pregabalin versus Placebo. mITT Population

\begin{tabular}{l|c|c}
\hline Measure & Baseline & Maintenance \\
\hline HAD scale (\% of Pts) & Pregabalin 18 pts & Pregabalin 18 pts \\
\hline & Anxiety score $>11:(45 \%)$ & Anxiety score $>11:(10 \%)$ \\
\hline & Depression score $>11:(30 \%)$ & Pepression score $>11:(5 \%)$ \\
\hline & Placebo 16 pts & Anxiety score $>11:(50 \%)$ \\
\hline & Anxiety score $>11:(38 \%)$ & Depression $>11:(28 \%)$ \\
\hline HIT-6 score (mean value) & Depression score $>11:(26 \%)$ & Pregabalin 18 pts \\
\hline & Pregabalin 18 pts & $(50)$ \\
\hline & $(>60)$ & Placebo 16 pts \\
\hline EQ-5D (VAS mean value)* & Placebo 16 pts & $(>60)$ \\
\hline & $(>60)$ & Pregabalin 18 pts \\
\hline & Pregabalin 18 pts & $(69 \%)$ \\
\hline & $(48.9 \%)$ & Placebo 16 pts \\
\hline
\end{tabular}

HAD $=$ Hospital Anxiety and Depression scale; HIT-6 = Headache Impact Test

*VAS (visual analog scale): $0 \%=$ worst value, $100 \%=$ better value

genic refers to the suspected origin of the pain. The obligatory symptoms of cervicogenic headache are: a unilateral pain constantly on the same side, aggravated by particular movements of the cervical spine or external pressure applied to the ipsilateral neck or occipital region. It is experienced as a continuous unilateral cervical and hemicranial pain. Occipital nerve, facets, and nerve roots may respond to blockade with local anesthetics (refer to reference 7 for details)

The pain is dull, tearing, boring, and burning in quality. An important diagnostic feature of cervicogenic headache is a transient pain-free interval after anesthetic blockade of the $\mathrm{C} 2$ roots or the greater occipital nerve on the symptomatic side.

Cervicogenic headache is sometimes preceded by cervical whiplash injury as those subjects who suffer acute neck pain after whiplash have a three times greater risk of developing chronic neck pain. According to the Oslo whiplash study, cervicogenic headache was diagnosed in $8 \%$ of whiplash patients after 6 weeks. ${ }^{29}$ In post-traumatic headache, symptoms were identical to cervicogenic headache in many instances but unilaterality of pain occurred in $24 \%$ of patients. ${ }^{30}$ The pain of cervicogenic headache appears to be transmitted via thin unmyelinated C-fibers. ${ }^{31}$ Pain impulses from the occipital region of the head and neck enter the spinal cord via the C2-C5 dorsal rami, ${ }^{32,33}$ the $\mathrm{C} 2$ root probably plays a central role in pain transmission. Intrathecal nerve roots are more vulnerable to injury than peripheral nerves due to their lesser connective tissue covering and their greater vascularity, ${ }^{34}$ and an injured nerve root and

Table 7: Patient Global Impression of Change (PGIC), mITT Population

\begin{tabular}{l|c|c|c}
\hline & $\begin{array}{c}\text { PREGABALIN } \\
\text { N-18 }\end{array}$ & $\begin{array}{c}\text { PLACEBO } \\
\mathbf{N}-16\end{array}$ & $\begin{array}{c}\text { Test statistic } \\
\mathbf{N = 3 4} \mathbf{P = 0 . 0 1 5}\end{array}$ \\
\hline IMPROVED & $85 \%$ & $23 \%$ & \\
\hline NO CHANGE & $5 \%$ & $43 \%$ & \\
\hline WORSE & $10 \%$ & $34 \%$ & \\
\hline
\end{tabular}

dorsal root ganglion may be a cause of chronic pain secondary to neck sprain. $^{35}$

In this study, pregabalin improved the frequency of headache days by ten days per month in the second month; which is remarkable, considering the long-term potentiation and wind-up in these patients. Headache intensity reduced from moderate to mild compared to placebo. Patents on pregabalin who were depressed or anxious improved; possibly because of pain reduction, improved sleep, increased hope of improvement or because of the anxiolytic properties of pregabalin. For many patients on pregabalin, the headache impact test improved, reducing their score to less than 60 . Results measured with the Patients Global Impression of Change were significantly in favor of active pregabalin treatment. Seventy five percent of patients on placebo escalated to the maximum dose of $450 \mathrm{mg}$. and $52 \%$ of patients on placebo discontinued because of lack of efficacy or withdrew consent.

The most common adverse events were: somnolence, nausea, and peripheral edema, even though patients in the active group maintained their participation because of the benefit they obtained. The occasional patient with ankle edema suspected he was on the active drug.

Table 8: Summary of Adverse Events - Safety Population

\begin{tabular}{l|c|c|c}
\hline & N & $\begin{array}{c}\text { Placebo } \\
\mathbf{N = 2 1}\end{array}$ & $\begin{array}{c}\text { Pregabalin } \\
\mathbf{N = 2 0}\end{array}$ \\
\hline Number ofAdverse events & & 6 & 36 \\
\hline Subjects with Adverse events & 41 & $24 \%(5)$ & $75 \%(15)$ \\
\hline $\begin{array}{l}\text { Subjects with adverse events Relationship/ } \\
\text { unknown relationship }\end{array}$ & 20 & & \\
\hline $\begin{array}{l}\text { Subjects with: } \\
\text { Serious adverse events }\end{array}$ & 41 & $0 \%(1)$ & $80 \%(12)$ \\
\hline $\begin{array}{l}\text { Subjects with: } \\
\text { Adverse events causing study drug discontinuation }\end{array}$ & 41 & $10 \%(2)$ & $0 \%(0)$ \\
\hline
\end{tabular}

$\mathrm{N}=$ the number of subjects analysed. 
Table 9: Summary of Adverse Events by System Organ Class - Safety Population

\begin{tabular}{l|c|c}
\hline Events & Placebo $(\mathbf{N}=\mathbf{2 1})$ & Pregabalin $(\mathbf{N}=\mathbf{2 0})$ \\
\hline Nervous system disorders & 1 & 11 \\
\hline Somnolence & 0 & 8 \\
\hline Dizziness & 1 & 3 \\
\hline General disorders & 0 & 4 \\
\hline Edema peripheral & 0 & 4 \\
\hline Gastrointestinal disorders & 1 & 4 \\
\hline Dry mouth & 0 & 2 \\
\hline Nausea & 1 & 2 \\
\hline Psychiatric disorders & 0 & 2 \\
\hline Confusional state & 0 & 2 \\
\hline
\end{tabular}

Most frequent adverse events

$\mathrm{N}=$ the number of subjects analysed.

Patient selection in this study was very difficult for four reasons: No patients with migraine were included and family history of migraine was scrutinized. Previous use of pregabalin was not permitted; pregabalin is a frequently prescribed drug. Patients refused to participate because of a 1:1 risk of receiving a placebo and many patients were desperate and in need of an active treatment for their chronic daily cervicogenic headache.

\section{Conclusion}

Forty one patients were recruited. In this study both the placebo and pregabalin groups had, on average, 26 headache days per month at baseline. The difference between placebo and pregabalin was statistically significant only for the second half of their maintenance period, reducing the number of headache days per month by ten days. In the first half of the maintenance phase a reduction of seven days per month also showed a trend of improvement. There are no significant studies on the use of medication for cervicogenic headache. In our clinical experience, chronic cervicogenic headache seems unresponsive to common headache medication. Patients with chronic daily cervicogenic headache are severely afflicted but a change from baseline in the headache-related disability occurred in the pregabalin group. Their involvement in a double blind clinical study was very difficult. Although this was a small study, positive results suggest that large multi-site trials are warranted.

\section{ACKNOWLEDGEMENTS AND FUnding}

This study was funded by Pfizer Inc., Québec, Canada, through an unrestricted research grant. Biostatistics: Integrated Research, Dollard-Des-Ormeaux (Québec) Canada.

\section{REFERENCES}

1. Headache Classification Subcommittee of the International Headache Society. The International Classification of Headache Disorders: 2nd edition. Cephalalgia. 2004;(24Suppl 1):9-160.

2. Sjaastad O, Saunte C, Hovdal H, et al. Cervicogenic headache and hypothesis. Cephalalgia. 1983;3(4):249-56.
3. Fredriksen TA, Hovdal H, Sjaastad O. Cervicogenic headache clinical manifestation. Cephalalgia. 1987;7(2):147-60.

4. IHS headache classification committee of the International headache society. Classification and diagnostic criteria for headache disorders, cranial neuralgias and facial pain. Cephalalgia. 1988; (suppl. 7):1-96.

5. Sjaastad O, Fredriksen TA, Pfaffenrath. Cervicogenic headache diagnostic criteria. Headache. 1990;30(11):725-6.

6. Merskey H, Bogduk N. Classification of chronic pain. Description of chronic pain syndromes and definition of pain terms. Cervicogenic headache. 1994; 2nd ed. Seattle: IASP.

7. Sjaastad O, Fredriksen TA, Pafeffenrath V. Cervicogenic headache: diagnostic criteria. The cervicogenic international study group. Headache. 1998;38(6):442-5.

8. Sjaastad O, Fredriksen TA. Cervicogenic headache: criteria, classification, epidemiology. Clin Exp Rheumatol. 2000;18(2 Suppl. 19): S3-6.

9. Nilsson $\mathrm{N}$. The prevalence of cervicogenic headache in a random population sample of 20-59 years old. Spine. 1995;20(17): 1884-1888.

10. Fredriksen TA, Fougner R, Tangerud A. Cervicogenic headache. Radiological investigations concerning headache and neck. Cephalagia. 1989;9(2):139-46.

11. Merskey H, Bogduk N. ed. Classification of Chronic Pain. IASP 1994. 5. WCHS. Taxonomical definition of cervicogenic headache Available from: www.cervicogenic.com/definit1.htm 1994.

12. Bovim G, Berg R, Dale LG. Cervicogenic headache: anesthetic blockades of cervical nerves (C2-C3) and facet joints (C2-C3). Pain. 1992;49(3):315-20.

13. Martelletti P, Di Sabato F, Granata M. Failure of long term results of epidural steroid injection in cervicogenic headache [letter]. Eur Rev Med Pharmacol Sci. 1998;2(1):10.

14. Hack G. Cervicogenic headache: new anatomical discovery provides the missing link. Chiropr Rep. 1998;12(3):145-8.

15. Luo D Z, Chaplan SR, Higuera ES, et al. Upregulation of dorsal root ganglion alpha 2delta calcium channel subunit and its correlation with allodynia in spinal nerve-injured rats. Neurosci. 2001, Mar 15 21(6):1868-75.

16. McClelland D, Evans RM, Barkworth L, Martin DJ, Scott RH. A study comparing the actions of gabapentin and pregabalin on the electrophysiological properties of cultured DRG neurons from neonatal rats. BMC Pharmacol. 2004;4(14): $1-26$.

17. Field $\mathrm{M}$. The analgesic actions of pregabalin are mediated through its binding to the alpha 2 delta 1 subunit of voltage gated calcium channels. J Pain. 2004;5(3 suppl. 1):59.

18. Dooley DJ, Donavan CM, Meder WP, Whetzel SZ. Preferential action of gabapentin and pregabalin at P/Q-Type voltagesensitive calcium channels: inhibition of K-evoked $[\mathrm{H}]-$ norepinephrine release from rat neocortical slices. Synapse. 2002;45:171-90.

19. Wallin J, Cui J-G, Yakhnitsa V, Schechtmann G, Meyerson BA, Lenderoth B. Gabapentin and pregabalin suppress tactile allodynia and potentiate spinal cord stimulation in a model of neuropathy. Eur J Pain. 2002;6:261-72.

20. Field M.J, McCleary S, Hughes J, Singh L. Gabapentin and pregabalin, but not morphine and amitriptyline, block both static and dynamic components of mechanical allodynia induced by streptozocin in the rat. Pain. 1999;80:391-8.

21. Bogduk N. An overview of the international congress on whiplash associated disorders. Pain Res Manage. 2003;8(2): 103-5.

22. Ben-Menachem E. Pregabalin pharmacology and its relevance to clinical practice. Epilepsia. 2004;45(Suppl. 6):13-8.

23. Sauro KM, Rose MS, Becker WJ, et al. HIT-6 and Midas as measures of headache disability in headache referral population. Headache. 2010;50:383-95.

24. Zigmond AS, Snaith RP. The Hospital Anxiety and Depression Scale. Acta Pschiat Scand. 1983;67:361-70.

25. Oakes JM, Feldman HA. Statistical power of non equivalent pretestpost test designs: the impact of change-score versus ANCOVA models. Eval Rev. 2001, Feb 25(1):3-28. 
26. Vickers AJ, Altman DJ. Analysing controlled trials with baseline and follow up measurements. BMJ. 2001, Nov 325(7321):1123-4.

27. Stephen Senn. Change from baseline and analysis of covariance revisited. Stat Med. 2006;25:4334-44.

28. Edmeads J, Soyka D. Headache associated with disorders of skull and cervical spine. In Olesen J, Tfelt-Hansen P, Welch KMA editors. The Headaches. 1993. New York: Raven Press. p. 741-5.

29. Pollmann W, Keidel M, Pfaffenrath V. Headache and the cervical spine: a critical review. Cephalalgia. 1997;17:801-16.

30. Magnusson T. Extracervical symptoms after whiplash trauma. Cephalalgia. 1994;14:223-7.
31. Groenbaek E. Cervical antero-lateral microsurgery for headache. In Pfaffenrath V, Lundberg PO, Sjaastad O editors. Updating in Headache. Berlin:Springer-Verlag; 1985:17-23.

32. Kerr FWL. Central relationships of trigeminal and cervical primary afferents in spinal cord and medulla. Brain Res. 1972;43:561-72.

33. Bogduk N. Cervical causes of headache. Cephalalgia. 1989;9 (suppl 10):172-3.

34. Rydevic B, Brown MD, Lundborg G. Pathoanatomy and pathophysiology of nerve root compression. Spine. 1984;9:7.

35. Taylor JR, Twomey LT, Kakula BA. Dorsal root ganglion injuries in 109 blunt trauma fatalities. Injury. 1998;29(5):335-9. 